\title{
Protein identification from dried nipple aspirate fluid on Guthrie cards using mass spectrometry
}

\author{
LUCAS DELMONICO ${ }^{1,2}$, VIVIAN RABELLO AREIAS ${ }^{1}$, RODRIGO CÉSAR PINTO ${ }^{1}$, CINTIA DA SILVA MATOS ${ }^{1,3}$, \\ MARCO FELIPE FRANCO ROSA ${ }^{4}$, CAROLINA MARIA DE AZEVEDO ${ }^{4}$ and GILDA ALVES ${ }^{1,2}$ \\ ${ }^{1}$ Applied Genetics Laboratory, Haematology Service, National Cancer Institute, Rio de Janeiro, 20230-130; \\ ${ }^{2}$ Medical Sciences Graduation Program, Medical Sciences Faculty, State University of Rio de Janeiro, Rio de Janeiro, 20550-170; \\ ${ }^{3}$ Clinical Pathology Laboratory, National Cancer Institute, Rio de Janeiro, 20230-130; ${ }^{4}$ Radiology Service, \\ Gaffrée e Guinle University Hospital, Rio de Janeiro, 20270-004, Brazil
}

Received May 31, 2014; Accepted February 11, 2015

DOI: $10.3892 / \mathrm{mmr} .2015 .3432$

\begin{abstract}
Nipple aspirate fluid (NAF) requires investigation as a potential source of biomarkers for early diagnosis or risk assessment in breast cancer and other breast disorders The present study demonstrated that proteins were easily extracted from dried NAF spots on Guthrie cards and were suitable for mass spectrometry analysis. NAF was obtained from 80 women, collected on Guthrie cards, between 2007 and 2010. The NAF-proteins were extracted from the card by incubating the card in water. These proteins were then quantified and separated using one-dimensional, 12\% SDS-PAGE, gel electrophoresis and on high-resolution gradient gels at different concentrations (4-12, 8-16 and 4-20\%). The bands with the most abundant proteins were excised from the gradient gels and the proteins were identified by liquid chromatography quadrupole time of flight. Immunoglobulins, $\mathrm{Zn}-\alpha 2$-glicoprotein, apoliprotein D and prolactin inducible protein were among those identified. The NAF-Guthrie card collection method has not been applied previously, however, NAF proteins have been identified using other collecting techniques, confirming the feasibility of the NAF Guthrie card collection method for analyzing the proteins within NAF. The NAF-Guthrie card collecting method has multiple advantages, including being inexpensive, non-invasive, reliable and painless, and the cards can be stored at room temperature. Examining NAF may assist in identifying individuals at a higher risk of breast cancer and in improving patient prognosis.
\end{abstract}

Correspondence to: Professor Gilda Alves, Applied Genetics Laboratory, Haematology Service, National Cancer Institute, Pç. da Cruz Vermelha, 23, $6^{\circ}$ andar, Rio de Janeiro 20230-130, Brazil E-mail: gbrown@inca.gov.br

Key words: nipple aspirate fluid, breast neoplasms, proteome, mass spectrometry, Guthrie card

\section{Introduction}

Breast cancer is the most commonly diagnosed type of cancer in female individuals, and $99 \%$ of the cases of breast cancer originate in the ductal and lobular epithelia $(1,2)$. The breast cancer screening tools available at present, including mammography and careful palpation of the breasts do not detect up to $40 \%$ of early cases of breast cancer and are the least effective in detecting cancer in young females, whose tumors are often more aggressive (2). In addition, further invasive diagnostic methods, including needle aspiration or surgical biopsy, are required to determine whether the breast lesion is cancerous (3). Despite the use of mammography, breast cancer is often undetected at an early stage in Brazil (4). Thus, the development of a noninvasive and effective method to diagnose early-stage breast cancer is necessary to improve patient prognosis.

Nipple aspirate fluid (NAF) is continuously secreted and reabsorbed in non-pregnant and non-lactating women from the ductal and lobular system of the breast (5). NAF is a potential source of biomarkers for the early diagnosis or risk assessment of breast cancer, it is produced at all ages between puberty and the menopause, and can arise from malignant breast tumors and benign diseases, including inflammation, fibrocystic diseases and ductal ectasia (6).

As currently used techniques for the collection of NAF are either invasive or are pump-based, the application of Guthrie cards for collecting small quantities of NAF for subsequent protein extraction was investigated in the present study. Guthrie cards are routinely used for the collection of blood spots from heel prick assessements in newborns, to screen for metabolic disorders, including phenylketonuria. In addition, Guthrie cards are appropriate for protein conservation (7).

The present study aimed to investigate whether proteins can be extracted from dried NAF spots on Guthrie cards. In order to verify the feasibility of this method, a qualitative proteomics analysis was performed using liquid chromatography quadrupole time of flight (LC-Q-TOF) for certain proteins obtained by this method, which were separated in high-resolution gradient gels. 


\section{Materials and methods}

Subjects. The Ethical Committees from the Gaffrée e Guinle University Hospital (Rio de Janeiro, Brazil) approved subject participation for the present study; written informed consent was obtained from all patients. Between May 2007 and December 2010, 88 eligible female individuals, $\geq 18$ years old, were recruited with spontaneous nipple discharge at HUGG. Reasons for exclusion included pregnancy, lactation within the last 12 months, previous subareolar or other surgery, which may have disrupted the ductal systems and immunological deficiency by virus. Certain individuals had specimens analyzed from one breast only, whereas others had specimens analyzed from two breasts. In 50 females, NAF was secreted from one breast, whereas NAF was secreted from both breasts in 28 females. As for the origin of the discharge, certain females exhibited effusion from one orifice in the nipple, while others exhibited multiple orifices in the nipple, providing spontaneous NAF. Specimens were only collected when the NAF was easily obtainable. The NAFs were classified by their macroscopic characteristics, including whether they were watery, citrine, serous, bloody or mixed (seropurulent). All participants were subject to mammography and breast ultrasonography examinations and clinical evaluation.

NAF collection. NAF was collected using a modification of a previously described technique $(8,9)$. The participants had their breasts warmed for 10-30 min using bilateral hot compress pads wrapped in towels. The nipple was cleaned with alcohol and the breast was gently massaged from the chest wall toward the nipple for $1 \mathrm{~min}$. Subsequently, the participant gently compressed the breast with two hands and the fluid, which appeared in the form of droplets, was collected onto Guthrie cards (GE Healthcare Bio-Sciences, Pittsburgh, PA, USA), as shown in Fig. 1 and were stored at room temperature (Fig. 2). Up to three attempts were made to obtain fluid on each breast. If no fluid appeared following the third attempt, the participant was considered a non-provider. The NAF-Guthrie cards used in the present study had been stored for a period of 2-4 years.

Protein extraction and gels. The Guthrie spots were cut into sections of $\sim 6 \mathrm{~mm}^{2}$ and each was incubated in $100 \mu 1$ double-distilled water for $30 \mathrm{~min}$ at $56^{\circ} \mathrm{C}$. The soluble NAF proteins were mixed with $1 \mu 1$ phenylmethanesulfonyl fluoride $(0.2 \mathrm{mg} / \mathrm{ml}$; Sigma-Aldrich, St. Louis, MO, USA) and measured using the bicinchoninic acid or Smith reagent methods (Pierce BCA Protein Assay kit; Pierce Biotechnology, Inc., Rockford, IL, USA) (10).

The NAF proteins were separated by polyacrylamide gel electrophoresis using SDS-PAGE and $\beta$-mercaptoethanol (Sigma-Aldrich). The stacking gel was prepared at room temperature using $4 \%$ acrylamide (Sigma-Aldrich) Tris- $\mathrm{HCl}$ (0.5 M pH 6.8; Sigma-Aldrich), containing 0.4\% SDS, and the separating gel was prepared at room temperature using $12 \%$ acrylamide Tris- $\mathrm{HCl}$ buffer (1.5 M, pH 8.8), containing $0.4 \%$ SDS (Sigma-Aldrich). The electrode buffer used was Tris-glycine $(0.025 \mathrm{M}$ Tris base and $0.192 \mathrm{M}$ glycine; pH 8.3; All from Sigma-Aldrich), containing 0.1\% SDS. Each sample (20 $\mu \mathrm{g}$ of each) was mixed with the sample buffer to a final concentration of $0.06 \mathrm{M}$ Tris- $\mathrm{HCl} \mathrm{pH} 6.8,2 \%$ SDS, $5 \% \beta$-mercaptoethanol, $10 \%$ glycerol and $0.025 \%$ bromophenol blue. The samples were heated to $95^{\circ} \mathrm{C}$ for $3 \mathrm{~min}$ and loaded onto the gel in the mini-Protean II system (Bio-Rad Laboratories, Inc., Hercules, CA, USA), running at $39 \mathrm{~mA} / 120 \mathrm{~V}$ for $90 \mathrm{~min}$ at room temperature. The molecular weight standard was BenchMark Protein Ladder (Invitrogen Life Technologies, Carlsbad, CA, USA). Following electrophoresis, the gels were fixed for $1 \mathrm{~h}$ in a solution of $40 \%(\mathrm{v} / \mathrm{v})$ aqueous ethanol (99.8\%; Sigma-Aldrich) and 10\% (v/v) acetic acid (Merck Millipore, Darmstadt, Germany) at room temperature. The gels were then washed for $30 \mathrm{~min}$ in fresh fixing solution and incubated with Coomassie Blue R-250 $0.2 \%$ diluted in fixative solution for $2 \mathrm{~h}$ at room temperature (Sigma-Aldrich). The gels were destained using fixative solution for $2 \mathrm{~h}$, followed by incubation in water at room temperature until complete destaining.

The NAF proteins were also separated using Amersham ECL high resolution gradient gels (GE Healthcare Life Sciences, Chalfont, UK), with concentrations of 4-12, 8-16 and 4-20\%. Total protein $(5 \mu \mathrm{g})$ was added onto the gel with sample buffer 1:1 (50 mM Tris-HCl, $\mathrm{pH} 6.8,2 \%$ SDS, $0.1 \%$ bromophenol blue and $10 \%$ glycerol). This system has a horizontal electrophoresis field and the gels comprise buffers, which improve the resolution of complex samples. The molecular weight standard used was Benchmark Protein Ladder (Invitrogen Life Technologies). Following electrophoresis, the gels were stained with Coomassie Blue R-250, according to the manufacturer's instructions, and were analyzed for protein integrity and the to determine the profile of the revealed bands.

Enzymatic digestion for nano(n)LC-Q-TOF. Selected bands, as described by Manello et al (11), were excised for destaining and were subjected to enzymatic digestion, according to Shevchenko et al (12) with modification of the destaining phase, where the bands were destained in a solution of $25 \mathrm{mM}$ ammonium bicarbonate ( $\mathrm{pH}$ 8.8/50\%; Sigma-Aldrich) and acetonitrile (ACN) overnight in a shaker, at room temperature. All the samples were concentrated in a Speed-Vac Centrifuge (Thermo Fisher Scientific, Waltham, MA, USA) at 3,000 x g for $5 \mathrm{~min}$ to produce a $20 \mu \mathrm{l}$ final volume of digested ultrafiltrate sample (DIUs).

Analysis of DIUs by $n L C-Q-T O F$. Prior to the $\mathrm{nLC}-\mathrm{Q}-\mathrm{TOF}$ analysis of the DIUs, they underwent manual desalination Zip Tip (Eppendorf, Hamburg, Germany). Each Zip Tip was activated with $10 \mu \mathrm{l}$ ACN (100\%; Merck Millipore), was washed three times with $10 \mu l$ ultrapure sterile water, and $10 \mu l$ sample was loaded by pipetting up and down 10 times within the tube. Each Zip Tip was then washed three times using sterile ultrapure water, and ACN elution was performed. Subsequently, the samples were reduced to a final volume of $20 \mu \mathrm{l}$ and were stored at $-20^{\circ} \mathrm{C}$ until analysis using mass spectrometry (Q-TOF Ultima Global; Waters, Manchester, UK).

The extracted peptides from the SDS-PAGE gel slice were loaded into an electrospray ionization quadrupole time-of-flight (ESI-Q-TOF) mass spectrometer (Waters Corporation, Wilmslow, UK). The DIU samples were loaded onto the Waters nanoACQUITY UPLC ${ }^{\circledR}$ System (Waters Corporation, Milford, MA, USA), with a Waters Opti-Pak C18 trap column coupled 
Table I. Classification of the breast fluid collected.

\begin{tabular}{lcc}
\hline Type & Number & $\%$ \\
\hline Watery & 18 & 17 \\
Citrin & 5 & 5 \\
Serous & 35 & 33 \\
Blood & 12 & 11 \\
Mixed (seropurulent) & 36 & 34
\end{tabular}

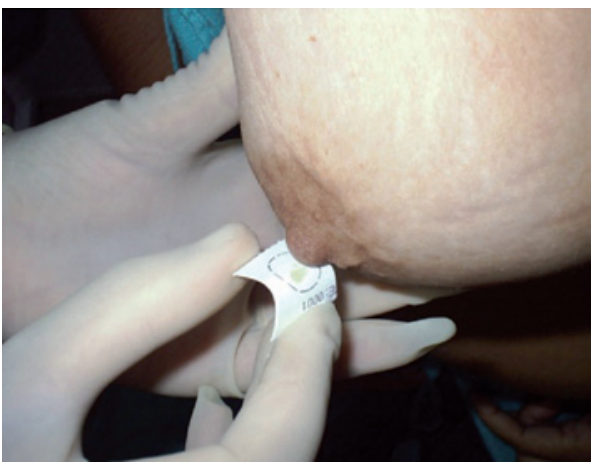

Figure 1. Collection of nipple aspirate fluid onto the Gurthrie card.

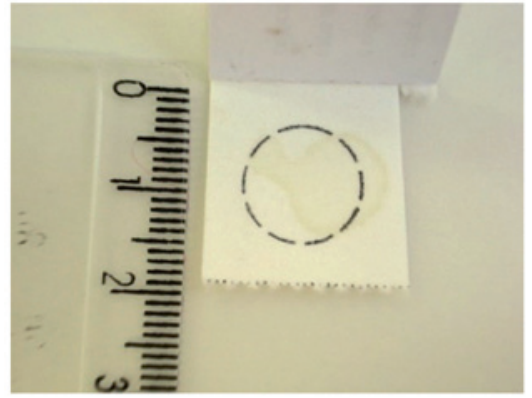

Figure 2. Nipple aspirate fluid spot absorbed onto the Guthrie card.

to Q-Tof Ultima ${ }^{\circledR}$ (Waters Corporation, Milford, MA, USA). Subsequently, $3.0 \mu \mathrm{l}$ sample was injected into a nanoEase C18 $150 \mathrm{mM}$ x $75 \mu \mathrm{m}$ column (Waters Corporation) at a flow rate of $0.6 \mu \mathrm{l} / \mathrm{min}$, and eluted with ACN containing $0.1 \%$ formic acid. The instrument control and data acquisition were performed using a MassLynx data system (Version 4.0, Waters Corporation). The experiments were performed by scanning from a mass-to-charge ratio $(\mathrm{m} / \mathrm{z})$ of between 200 and 2,000. The exact mass was automatically determined using the Q-Tof's LockSpray ${ }^{\mathrm{TM}}$ (Waters Corporation, Milford, MA, USA).

Database searching. The data were processed using ProteinLynx Global Server (version 2.0, Waters Corporation) for ESI-Q-TOF analysis. The proteins were identified by the correlation of tandem mass spectra to the NCBInr proteins and MSDB database, using MASCOT online software (www.matrixscience.com). The first analysis considered all taxonomies, while the second analysis was restricted to Homo sapiens to remove redundant protein identification.

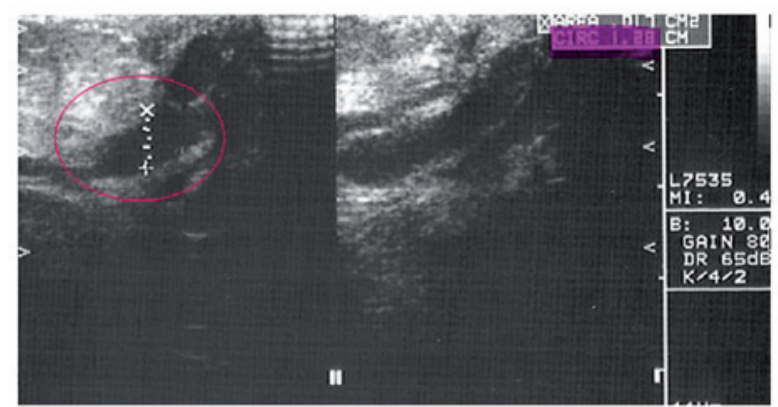

Figure 3. Ultrasonography revealing ductal ectasia on the left and right sides. The pink circle was added by the radiologist to emphasize the duct.

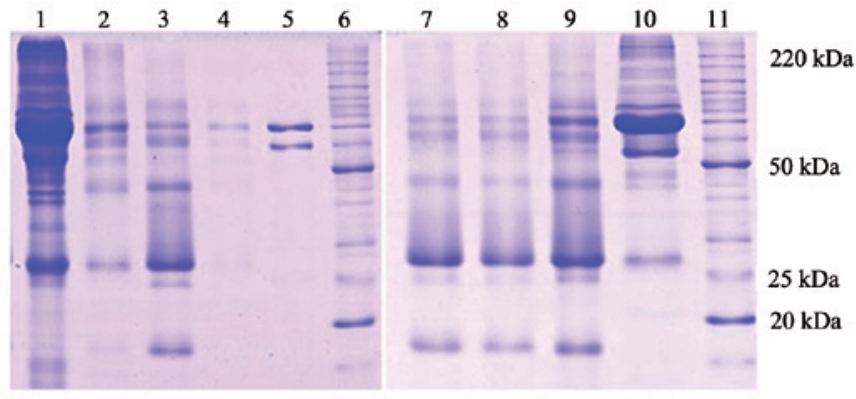

Figure 4. One-dimensional electrophoresis of the NAF proteins stained with Coomassie Brilliant Blue R-250. Lane 1, bloody NAF; lanes 2, 3 and 4 watery NAF; lane 5, bovine serum albumin; lanes 6 and 11 molecular weight; lanes 7, 8 and 9, mixed NAF; lane 10, citrine NAF. NAF, nipple aspirate fluid.

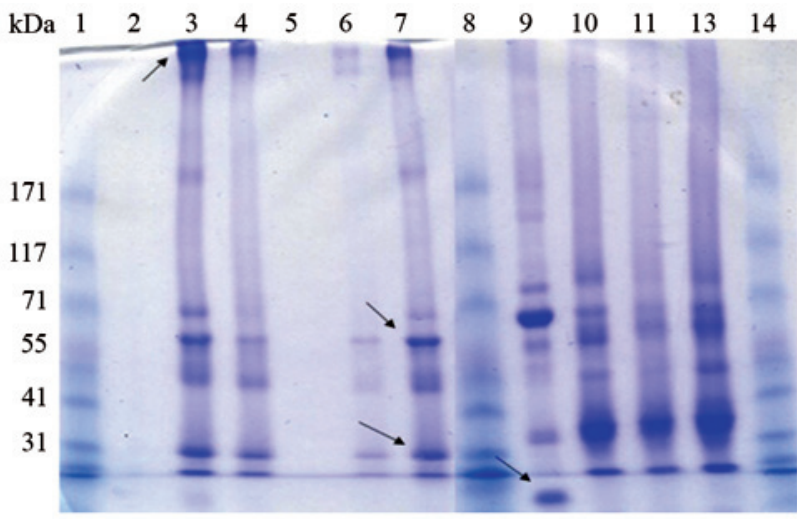

Figure 5. High resolution gradient gel 4-12\% electrophoresis of the NAF proteins. Lanes 1, 8 and 13, molecular weight; lanes 2 and 5, blanks; lanes 3 and 7, bloody NAF; lanes 4 and 10, mixed NAF, lane 6, watery NAF; lane 9 , citrine NAF; lanes 11 and 12, serous NAF. Arrows indicate the bands that were excised for subsequent proteomic analysis. NAF, nipple aspirate fluid.

Breast imaging. Conventional mammography was performed in a Mediman HFG/B unit with Kodak min-R-2000 film and a Kodak RP-X-Omat processor (Kodak, Rochester, NY, USA). Ultrasonography was used as a complementary examination to the conventional mammography, and was performed using an Image Point Hx unit (HP Labs, Palo Alto, CA, USA), with two transducers $(7.5$ and $10 \mathrm{MHz})$ that measured the diameters of the breast ducts. The images were then classified using a breast imaging reporting and data system (BI-RADS). 
Table II. List of the major proteins identified by liquid chromatography quadrupole time of flight.

\begin{tabular}{|c|c|c|c|c|}
\hline Band position & Protein & $\begin{array}{c}\text { Score } \\
(\text { Ion score }>50)\end{array}$ & Mass $(\mathrm{m} / \mathrm{z})$ & Match (n) \\
\hline \multirow[t]{8}{*}{$15(\mathrm{kDa})$} & Hemoglobin subunit $\beta$ & 1937 & 16102 & 59 \\
\hline & Hemoglobin subunit $\delta$ & 760 & 16159 & 36 \\
\hline & Prolactin-inducible protein & 523 & 16847 & 25 \\
\hline & Apoliprotein D (fragment) & 219 & 15305 & 27 \\
\hline & Ig $\alpha-1$ chain $C$ region & 214 & 38486 & 11 \\
\hline & $\operatorname{Ig} \gamma-1$ chain $\mathrm{C}$ region & 81 & 36596 & 3 \\
\hline & Putative zinc- $\alpha$-2-glycoprotein-like 1 & 79 & 23080 & 4 \\
\hline & Immunoglobulin J chain (Fragment) & 78 & 18509 & 2 \\
\hline \multirow[t]{5}{*}{$20(\mathrm{kDa})$} & Serum albumin & 4942 & 71317 & 163 \\
\hline & Apoliprotein D & 880 & 24541 & 40 \\
\hline & Clusterin (fragment) & 147 & 33794 & 9 \\
\hline & Prolactin-inducible protein & 132 & 16847 & 12 \\
\hline & $\alpha-1$-Antitrypsin & 54 & 46878 & 2 \\
\hline \multirow[t]{17}{*}{$50(\mathrm{kDa})$} & Ig $\alpha-1$ chain $\mathrm{C}$ region & 1483 & 38486 & 59 \\
\hline & $\operatorname{Ig} \alpha-2$ chain $\mathrm{C}$ region & 1483 & 37301 & 62 \\
\hline & Apoliprotein D & 777 & 24541 & 36 \\
\hline & Serum albumin & 625 & 71317 & 23 \\
\hline & Ig heavy chain V-III region BRO & 291 & 13332 & 9 \\
\hline & Ig heavy chain V-III region CAM & 102 & 13773 & 6 \\
\hline & Prolactin-inducible protein & 227 & 16847 & 15 \\
\hline & Complement $\mathrm{C} 4 \beta$ chain & 172 & 194351 & 3 \\
\hline & $\alpha-1$-Antitrypsin & 154 & 46878 & 9 \\
\hline & $\operatorname{Ig} \gamma-1$ chain $\mathrm{C}$ region & 140 & 36596 & 13 \\
\hline & Secretoglobin family 1D member 2 & 117 & 10260 & 6 \\
\hline & Zinc- $\alpha$-2-glycoprotein & 101 & 34465 & 7 \\
\hline & Polymeric immunoglobulin receptor & 88 & 84429 & 7 \\
\hline & Vasorin & 79 & 72751 & 2 \\
\hline & Ig $\kappa$ chain $\mathrm{C}$ region & 75 & 11773 & 6 \\
\hline & $\operatorname{Ig} \gamma-2$ chain $\mathrm{C}$ region & 68 & 36505 & 9 \\
\hline & Chromosome-associated kinesin KIF4A & 54 & 141390 & 2 \\
\hline \multirow[t]{3}{*}{200 (kDa) } & Serum albumin & 1290 & 71317 & 60 \\
\hline & Apoliprotein D (fragment) & 102 & 24541 & 8 \\
\hline & Cdc42 effector protein 4 & 53 & 30253 & 2 \\
\hline
\end{tabular}

Bold font represents the most abundant proteins in the nipple aspirate fluid. Ion score indicates the reliability of the results. Ig, immunoglobulin.

\section{Results}

From the 88 female individuals enrolled in the present study, NAF was obtained from $80(91 \%)$ on the first visit, which was collected and absorbed onto Guthrie cards, using the gentle massage and warming procedure. Of these 80 individuals, two were excluded due to subsequently identified immunological deficiency, and the remaining group was composed of 78 individuals, with a mean age of 50.24 years (range: $23-77$ years) and menarche at a mean age of 13.24 years (range: 9-18 years). A total of $43(55 \%)$ were postmenopausal. The mean age at menopause was 48.58 years (range: $36-54$ years). A total of 64 became pregnant and of these, 11 did not breastfeed. Of the total group, 18 individuals $(23 \%)$ had either an abortion $(8 ; 44 \%)$ or a miscarriage $(10 ; 66 \%)$. A total of 52 women $(67 \%)$ reported a family history of cancer, however, only four reported a family history of breast cancer, of which there was only one confirmed case of hereditary breast cancer. The results of the mammography examinations assigned $73 \%$ of the individuals to the BI-RADS 0 category (inconclusive diagnosis), which required additional assessments, $46 \%$ of which had ultrasonography and $77 \%$ were identified as BI-RADS 3 (benign lesions). Ultrasound was performed, which revealed the predominance of ductal ectasias (Fig. 3). In addition, other injuries were observed, including the presence of nodules, axillary lymph nodes and microcalcification.

A total of 106 NAF spots were obtained on the Guthrie cards, which were characteristically classified into the following five 
types: Watery, citrine, serous, bloody and mixed (Table I). NAF was obtained from both breasts in 28 of the females, explaining why the total number of NAF spots was higher than the number of individuals enrolled. The NAF classification from both breasts were the same, with the exception of three cases.

The protein concentration of NAF ranged between 6.8 and $11.2 \mu \mathrm{g} / \mu \mathrm{l}$, with a mean value of $9.2 \mu \mathrm{g} / \mu 1$. Analysis of the NAF proteins was performed using one-dimensional SDS-PAGE $12 \%$ gel electrophoresis, which revealed five major bands, with each sample containing similar quantities of protein. Using the Guthrie card collection method, the proteins were found to have a similar band pattern as those described by Mannello et al and Varnum et al using an aspiration system $(11,13)$. Differences from the default bands in the protein gel were classified according to band presence, absence and intensity variation (Fig. 4). No differences were observed in the bands in the watery and mixed NAF groups, compared to the higher molecular weight bands of the citrine group, between the gradient gels and the SDS-PAGE 12\% gels. The 4-12\% gel exhibited the highest resolution (Fig. 5) and was selected for use in the gradient gels. The greatest difference was confirmed in the bands $<20 \mathrm{kDa}$. This difference requires further investigation, but were considered to be associated with cystic breast disease and benign breast lesions $(13,14)$.

Of the bands excised, the spectra predominates were identified and the peptide score was calculated as $-10 \log (\mathrm{P})$, where $\mathrm{P}(0.05)$ is the probability that the observed match was a random event. Table II shows the major proteins that were identified with a score $>50$ in the nLC-Q-TOF. Immunoglobulins, Zn- $\alpha 2-$ Glicoprotein, apoliprotein D and prolactin inducible protein were among the bands assessed. The NAF-Guthrie card collection has not been applied previously, however, NAF proteins have been identified using other collecting methods $(11,15)$, confirming the feasibility of the NAF-Guthrie card collecting method.

\section{Discussion}

Examining the breast epithelium directly using core needle biopsy or ductal lavage is uncomfortable and invasive. By contrast, the NAF-Guthrie card collecting method is inexpensive, non-invasive, reliable and painless. This method may broaden the applicability of NAF sample collection and may have an advantage over the method described by Sauter et al (16), which used an aspiration device. In addition, Guthrie cards occupy little space and can be stored at room temperature with dried NAF. These characteristics enable the cards to be sent to a laboratory for analysis.

Identifying associations in the results of imaging techniques is hindered by their own limitations in the public health system in Brazil (4), however, a significant association was observed between ductal ectasia and the secretion of NAF. In addition, the majority of the mammogram results were BI-RADS 0 , which are flagged as abnormal due to the ability of non-palpable lesions to disturb results, leading to a false-negative diagnosis (17).

A low percentage of the female individuals selected for the present study were receiving hormone therapy or oral contraceptives (data not shown), which did not enable the investigation of associations between the secretion of NAF and these variables. The small $20 \mathrm{kDa}$ protein, in particular the Gross cystic disease fluid protein, as described by Mannello et al is markedly associated with alterations in the breast $(15,16)$. Human epidermal growth factor receptor-2 (HER2) is a breast cancer subtype biomarker, the amplification/overexpression of which is associated with aggressive disease and a poorer prognosis (18). In ductal carcinoma in situ, overexpression of HER has been observed by immunohistochemistry and is correlated with higher proliferative activity (19). HER2 has previously been detected in NAF, in addition to breast related hormones, metabolites and growth factors (18-24). Thus, it was suggested that breast cancer biomarkers can be detected using dried NAF spots in Guthrie cards, followed by mass spectrometric analysis. In the present study, gels were produced from the NAF proteins in order to characterize them; however, for clinical use, the shotgun mass spectrometry approach, with no in-between gel, is considered more appropriate.

In conclusion, the NAF-Guthrie card collecting method used in the present study, was confirmed as being suitable for modern mass spectrometric analysis. This method has potential application for early breast cancer screening and subtype classification.

\section{Acknowledgements}

The authors would like to acknowledge the Mass Spectrometry Facility at the Brazilian Biosciences National Laboratory, CNPEM (Campinas, Brazil) for their support in mass spectrometric analysis and Professors Márcia Regina Soares da Silva and Rosane Nunes from the Instituto de Química of Universidade Federal do Rio de Janeiro (Rio de Janeiro, Brazil) for their technical assistance.

This study was supported by the Fundação de Amparo a Pesquisa do Rio de Janeiro (noa. Bolsa 102.558/2012, APQ1 E-26/110.319/2008 and APQ1 E-26/110.803/2009) and the Programa de Oncobiologia, Rio de Janeiro, Brazil.

\section{References}

1. West KE, Wojcik EM, Dougherty TA, et al: Correlation of nipple aspiration and ductal lavage cytology with histopathologic findings for patients before scheduled breast biopsy examination. Am J Surg 191: 57-60, 2006.

2. Alexander H, Stegner AL,Wagner-Mann C, et al: Proteomic analysis to identify breast cancer biomarkers in nipple aspirate fluid. Clin Cancer Res 10: 7500-7510, 2004

3. Balci FL and Feldman SM: Exploring breast with therapeutic ductoscopy. Gland Surg 3: 136-141, 2014.

4. Liedke PE, Finkelstein DM, Szymonifka J, et al: Outcomes of breast cancer in Brazil related to health care coverage: a retrospective cohort study. Cancer Epidemiol Biomarkers Prev. 23: 126-133, 2014.

5. Lang JE and Kuerer HM: Breast ductal secretions: clinical features, potential uses, and possible applications. Cancer Control 14: 350-359, 2007.

6. Hirose M, NobusawaH and Gokan T: MR ductography: comparison with conventional ductography as a diagnostic method in patients with nipple discharge. Radiographics 27: S183-S196, 2007.

7. Guthrie R and Susi A: A simple phenylalanine method for detecting phenylketonuria in large populations of newborn infants. Pediatrics 32: 338-343, 1963.

8. Borte S, Janzi M, Pan-Hammarström Q, et al: Placental transfer of maternally-derived IgA precludes the use of guthrie card eluates as a screening tool for primary immunodeficiency diseases. PLoS One 7: e43419, 2012.

9. van Ommen CC, Elvers LH, Notermans DW, et al: Antibody levels against B. pertussis in neonates measured in dried blood spots. Vaccine 30: 2697-2700, 2012. 
10. Smith PK, Krohn RI, Hermanson GT, Mallia AK, Gartner FH, Provenzano MD, et al: Measurement of protein using bicinchoninic acid. Anal Biochem 150: 76-85, 1985.

11. Manello F, Medda V and Tonti GA: Protein profile analysis of the breast microenvironment to differentiate healthy women from breast cancer patients. Expert Rev Proteomics 43: 43-60, 2009.

12. Shevchenko A, Wilm M, Vorm O, et al: Mass spectrometric sequencing of proteins silver-stained polyacrylamide gels. Anal Chem 68: 850-858, 1996.

13. Varnum SM, Covington CC, Woodbury RL, et al: Proteomic characterization of nipple aspirate fluid: identification of potential biomarkers of breast cancer. Breast Cancer Res Treat 80: 87-97, 2003.

14. Sartorius OW, Smith HS, Morris P, et al: Cytologic evaluation of breast fluid in the detection of breast disease. J Natl Cancer Inst 59: 1073-1080, 1977.

15. Manello F, Tonti GA and Papa S: Human gross cyst breast disease and cystic fluid: bio-molecular, morphological, and clinical studies. Breast Cancer Res Treat 97: 115-129, 2006.

16. Sauter ER, Ross E, Daly M, et al: Nipple aspirate fluid: a promising non-invasive method to identify cellular markers of breast cancer risk. Br J Cancer 76: 494-501, 1997.

17. Hamy AS, Giacchetti S, Albiter M, et al: BI-RADS categorisation of 2,708 consecutive nonpalpable breast lesions in patients referred to a dedicated breast care unit. Eur Radiol 22: 9-17, 2012.
18. Borg A, Tandon AK, Sigurdsson H, et al: HER-2/neu amplification predicts poor survival in node-positive breast cancer. Cancer Res 50: 4332-4337, 1990.

19. Allred DC, Clark GM, Molina R, et al: Overexpression of HER-2/neu and its relationship with other prognostic factors change during the progression of in situ to invasive breast cancer. Hum Pathol 23: 974-979, 1992.

20. Kuerer HM, Thompson PA, Krishnamurthy S, et al: High and differential expression of HER-2/neu extracellular domain in bilateral ductal fluids from women with unilateral invasive breast cancer. Clin Cancer Res 9: 601-605, 2003

21. Gann PH, Geiger AS, Helenowski IB, et al: Estrogen and progesterone levels in nipple aspirate fluid of healthy premenopausal women: relationship to steroid precursors and response proteins. Cancer Epidemiol Biomarkers Prev 15: 39-44, 2006.

22. Loud JT, Gierach GL, Veenstra TD, et al: Circulating estrogen and estrogens within the breast among postmenopausal BRCA1/2 mutation carriers. Breast Cancer Res Treat 143: 517-529, 2014.

23. Fought AJ, McGathey C, Scholtens DM, et al: Hormonal determinants of nipple aspirate fluid yield among breast cancer cases and screening controls. Cancer Epidemiol Biomarkers Prev 22: 2277-2284, 2013

24. Tredwell GD, Miller JA, Chow HH, et al: Metabolomic characterization of nipple aspirate fluid by (1)H NMR spectroscopy and GC-MS. J Proteome Res 13: 883-889, 2014. 